\title{
LINGUAGEM E METÁFORA NOS CADERNOS DO CÁRCERE DE ANTONIO GRAMSCI ${ }^{1}$
}

\section{LUCIANA NOGUEIRA ${ }^{2}$, RENATO CÉSAR FERREIRA FERNANDES ${ }^{3}$}

\author{
Universidade do Vale do Sapucaí - UNIVÁS \\ Universidade Estadual de Campinas - UNICAMP \\ lulunog@yahoo.com.br, rcesarffeyahoo.com.br
}

\begin{abstract}
Resumo. $O$ presente trabalho é resultado de uma pesquisa em andamento e que se encontra em sua fase inicial. Assim, buscamos trazer o debate de um elemento pouco explorado no Brasil do pensamento de Antonio Gramsci, a saber: a relação entre a linguagem e a metáfora presente nos Cadernos do Cárcere. Para isso, abordamos a questão da linguagem como concepção de mundo, segundo o autor italiano, levando em conta as condições de produção sócio-históricas de suas formulações.
\end{abstract}

Palavras-chave: linguagem; metáfora; Antonio Gramsci.

\begin{abstract}
The present work is the result of a research in progress and that is in its initial phase. Thus, we try to bring the debate of an element not explored in Brazil from the thought of Antonio Gramsci, namely: the relation between the language and the metaphor present in the Prison Notebooks. For this, we approach the question of language as a conception of the world, according to the Italian author, taking into account the socio-historical conditions of production of its formulations.
\end{abstract}

Keywords: language; metaphor; Antonio Gramsci.

\section{Introdução}

O presente artigo é uma pesquisa introdutória acerca do conceito de linguagem e de metáfora nos escritos carcerários de Antonio Gramsci. Na juventude, Gramsci estudou linguística na universidade e nos trabalhos carcerários podemos notar em diversos momentos as questões em torno da língua e da linguagem, marcando, assim, umas das preocupações teóricas do autor. Sua obra é bastante particular: ela é composta por notas para uma investigação futura, sendo algumas reescritas, outras abandonadas e que nunca

\footnotetext{
${ }^{1}$ Este artigo é fruto de uma comunicação apresentada no Simpósio "Análise de discurso e conhecimento algumas palavras sobre ciências e tecnologias de linguagem", no $63^{\circ}$ Seminário do GEL (2015).

2 Doutora em Linguística pela Unicamp; professora no Programa de Pós-Graduação em Ciências da Linguagem da UNIVÁS. http://lattes.cnpq.br/7475342844385424.

${ }^{3}$ Doutorando em Ciências Políticas pela Unicamp. http://lattes.cnpq.br/5848740692010723.
} 
foram finalizadas por ele. Algumas delas, como o próprio autor afirma, escritas sem as obras de referência.

Gramsci nasceu em 1891. Iniciou os estudos de Letras na Universidade de Turim, mas nunca os concluiu. Na Universidade, ele chegou a trabalhar com Matteo Bartoli, linguista italiano que se contrapunha aos neogramáticos que dominavam a linguística italiana e europeia da época (IVES, 2004, p. 46). Na própria Universidade, entrou em contato com o movimento socialista e aos poucos foi se formando enquanto quadro do Partido Socialista Italiano, do qual foi jornalista e dirigente. Após a Revolução Russa de 1917, ajudou a fundar o Partido Comunista da Itália, do qual também foi um dos principais dirigentes.

Como forma de reação ao processo revolucionário russo, setores da classe dominante financiaram o movimento fascista do ex-socialista Benito Mussolini. O fascismo chegou ao poder em 1922, após a "Marcha sobre Roma". Com Mussolini no poder, a repressão às organizações operárias (socialistas e comunistas) foi intensa. Gramsci foi, então, preso pelos fascistas em 1926, quando era deputado.

A partir de 1929, Gramsci, no cárcere, começou a desenvolver anotações em cadernos. Ao todo produziu 29 cadernos, mais 5 de traduções. Essa obra, conhecida como Cadernos do Cárcere ${ }^{4}$, é um conjunto de notas de trabalho com o objetivo de escrever uma "análise futura" sobre temas variados como a história da Itália, debates com intelectuais italianos, crítica literária, análises linguísticas, entre outros temas. Como "notas de trabalho", os Cadernos resultam numa obra inacabada e, por isso, um estudo interpretativo dessa obra deve levar em conta esse caráter inconcluso e provisório das notas gramscianas 5 .

O presente artigo está embasado nessas notas carcerárias. Na primeira parte, recuperamos o contexto da linguística italiana no início do século XX. Na segunda parte, apresentamos as reflexões sobre a importância da "linguística" na obra gramsciana, a partir de alguns intérpretes dessa obra. Em seguida, apresentamos a concepção de linguagem formulada por Gramsci e passamos então à discussão da noção de metáfora.

É importante salientar que, seja na obra pré-carcerária ou na obra carcerária, Gramsci não tem uma concepção "rígida" ou "finalizada" de linguagem, tal como afirma Bentivegna sobre este tema:

No se trata, por supuesto, de un cuerpo sistemático de nociones, de una teoría articulada en un todo organizado, sino de un conjunto disperso que constituye, en su relación con el magma de escritos del que forman parte, una de las aproximaciones más lúcidas para pensar las

\footnotetext{
${ }^{4}$ Neste trabalho utilizamos a tradução brasileira realizada a partir da edição crítica italiana dos Quaderni del Carcere. Nos estudos gramscianos a edição brasileira é conhecida como um misto, já que não foram publicadas todas as notas de Gramsci como na edição crítica italiana de 1975, primeira edição completa. Além disso, na tradução brasileira há uma organização temática tal como nas edições anteriores. Sobre esse tema, ver Bianchi (2008, p. 44-45).

${ }^{5}$ Para o debate sobre o caráter inconcluso e provisório, ainda que orgânico, dessas notas, recomendamos a leitura de Bianchi, principalmente, o capítulo "Eterno/Provisório" (2008, p. 21-53).
} 
articulaciones entre los problemas del lenguaje, las cuestiones histórico-culturales y la praxis critica. (2013, p. 49)

Sobre este "magma de ideias e reflexões", propomos uma reflexão inicial e crítica, no sentido althusseriano: por meio da leitura, buscamos compreender aqueles conceitos em estado "prático" e apresentar caminhos para o desenvolvimento dos conceitos para um marco "teórico".

\section{Gramsci e a questão da língua italiana}

A formação do Estado nacional italiano é bastante tardia, se compararmos ao resto dos países da Europa Ocidental. O processo de unificação italiano iniciou em 1861 e terminou em 1870, com a incorporação de Roma (que estava sob a égide do Vaticano) e a região de Veneza. Essa unificação foi liderada pela burguesia do norte do país, da região de Piemonte. Esse processo foi largamente analisado por Gramsci que, se refere a isso, como um processo de "revolução passiva", isto é, um processo realizado pelas classes dominantes sem a incorporação ou participação ativa das classes subalternas ${ }^{6}$. É, neste sentido, que podemos entender a afirmação de Gramsci de que: "A burguesia unificou territorialmente o povo italiano; cabe à classe operária a tarefa de levar a cabo a obra da burguesia, de unificar econômica e espiritualmente o povo italiano" ([1921] 2004, p. 35).

Entre os problemas da unificação econômica e nacional, podemos dizer que existe uma "questão da língua", isto é, o problema da unificação em uma língua. Como demonstra Peter Ives, a burguesia nortista tentou resolver este problema através da criação de uma língua padrão, generalização do dialeto Toscano, utilizado em Florença, e sua imposição aos outros dialetos, incluindo o dialeto da Sardenha, região em que Gramsci nasceu (IVES, 2004, p. 38). Essa imposição linguística, para Gramsci, não pode ser separada da própria hegemonia burguesa italiana: é uma hegemonia que ao invés de incorporar os setores subalternos em sua própria composição, impõe a eles sua própria direção. Por isso, uma revolução passiva em todos os sentidos: política, econômica e cultural.

É afetado por esta questão da língua e pelo problema da hegemonia burguesa na Itália, que Gramsci estuda Letras em Turim. Estas são as condições de produção sóciohistóricas em que o autor está inserido. Já no primeiro ano, de acordo com Ives (ibidem, p. 31), ele entra em contato com o professor Matteo Bartoli. Esse contato acadêmico marcará sua compreensão sobre a linguística. Nestes anos, o debate acadêmico italiano, principalmente no campo da história das línguas e da filologia, tinha duas grandes teorias hegemônicas: a dos neogramáticos e a dos neoidealistas.

Para Gramsci, assim como para Bartoli, os neogramáticos representavam uma corrente teórica positivista no terreno dos estudos glotológicos. De acordo com Ives, essa escola defendia a teoria de que a mudança nas línguas acontecia por uma mudança no "som", isto é, que a mudança na pronúncia das palavras era o que ocasionava a mudança

${ }^{6}$ Sobre a revolução passiva e a unificação italiana, ver o Caderno 19. 
das línguas. Dessa forma, os teóricos neogramáticos desenvolveram todo um mapa das línguas europeias baseado no estudo dessas mudanças de som. Tudo isso, ancorado no estudo de leis que explicavam esse processo de mudança. De acordo com Ives,

To the Neogrammarians, the sounds whose changes were being explained could not be related to the meanings of the individual words in which they existed, except in so far as sound change is related to the other sounds within the word. But the social, political or cultural contexts of a word were to be disregarded. (ibidem, p. 50)

A outra escola teórica era a dos neoidealistas, cuja principal referência teórica foi Benedetto Croce 7 . Para ele, "the science of art and the science of language, the Aesthetic and the Linguistic, conceived as true and proper sciences are not two distinct things but one single science" (CROCE apud IVES, 2004, p. 53). Nesse sentido, de acordo com a concepção idealista do próprio Croce - a qual foi desenvolvida por linguistas que o seguiram, como Karl Vossler - a linguagem só poderia existir enquanto expressão, já que ela seria sempre uma aproximação do fenômeno real do discurso, mas não existiria enquanto objeto científico próprio, porque assim como o ato estético, a linguagem expressa é sempre particular, nunca repetível ${ }^{8}$.

Os neoidealistas, sobretudo Croce, criticavam a concepção positivista dos neogramáticos. Enquanto estes concebiam a linguagem como uma estrutura objetiva que muda com o tempo devido a suas próprias leis, os neoidealistas defendiam a impossibilidade de se encontrar leis ou uma estrutura objetiva capaz de ser um objeto de estudos científicos. Como afirma Bentivegna, para Croce a linguagem teria uma "natureza eterna" e "transhistórica" (2013, p. 32). A linguagem, nesse caso, era sempre particular.

De acordo com Ives, a crítica de Bartoli, compartilhada por Gramsci, a essas duas escolas teóricas, tem três aspectos principais: 1) A língua não pode ser separada da cultura, da sociedade e da história dos seus usuários, isto é, ela existe como um elemento dessa totalidade social; 2) A mudança na língua não pode ser explicada por leis gerais, pela fisiologia ou psicologia dos indivíduos, mas a partir da relação de interação entre as línguas e dialetos no interior das sociedades históricas; 3) A análise da mudança na língua pode ser analisada por meio do estudo da prática da linguagem pelos indivíduos, combinando o estudo da estrutura fonética, da sintaxe e da semântica.

Em determinado sentido, a crítica de Gramsci é a continuação da elaboração de Bartoli. Como ele próprio relata numa carta, falando sobre seu ex-professor:

[Bartoli] estaba persuadido de que yo era el arcángel destinado a devastar definitivamente a los "neogramáticos", porque él, de la misma generación y unido a través de miles de hilos académicos a essa horda de hombres infames, no quería ir en sus postulados más allá de un cierto

\footnotetext{
${ }^{7} \mathrm{O}$ pensamento de Gramsci foi bastante influenciado, principalmente na juventude, por Croce. O Caderno 10 reúne diversas notas do comunista italiano de crítica e análise da obra de Croce.

${ }^{8}$ Sobre isso, ver Bianchi (2008) sobre a teoria de Croce.
} 
límite fijado por las conveniencias y por la deferencia hacia viejos monumentos funerarios de la erudición. (2013, p. 62)

Será inserido nessas condições de produção, considerando esse cenário de debate da linguística italiana, a partir da questão da língua, que Gramsci formulará então sua concepção "em estado prático" de linguagem", chamando a atenção para a relação entre linguagem e metáfora, como veremos. Essa elaboração é parte de uma crítica muito mais ampla ao positivismo, inclusive no interior do marxismo. Mas, antes disso, retomaremos brevemente a discussão de alguns intérpretes de Gramsci sobre a importância da questão linguística nos Cadernos do Cárcere.

\section{A reflexão em torno da língua e da linguagem nos Cadernos do Cárcere}

Entre os estudiosos do tema, existe uma polêmica sobre o papel da reflexão linguística na teoria gramsciana: ela seria acessória ou fundamental no conjunto de sua teoria? Um dos primeiros a colocar essa questão foi Lo Piparo, pioneiro no debate linguístico em Gramsci, com sua obra Lingua, intelletuali, egemonia in Gramsci (1979). Para o linguista italiano:

a questão é simples: uma multiplicidade de indícios convergentes (testemunhos autobiográficos, anotações de contemporâneos, organização dos temas nos Cadernos, etc.) induz a formular a hipótese de que Gramsci amadureceu a teoria dos intelectuais, da hegemonia, da sociedade civil, etc., no curso dos seus interesses profissionais pela linguagem. Portanto, a matriz primitiva da sua filosofia não deveria ser buscada em Marx, em Lenin ou em qualquer outro marxista, mas na ciência da linguagem. (LO PIPARO, 2008)

O autor toma como base dois planejamentos para a elaboração dos Cadernos do Cárcere de Gramsci (um de março de 1927 e outro de novembro de 1930), nos quais as questões linguísticas aparecem como as principais preocupações teóricas do autor durante o período. Além disso, destaca Lo Piparo, que o último caderno, escrito integralmente em 1935, foi dedicado ao conceito de Gramática (Caderno 29).

Outro autor que aborda a reflexão linguística de Gramsci é Peter Ives. Em sua obra Language and Hegemony in Gramsci (2004), o autor estuda a concepção de linguagem presente em toda a obra gramsciana, incluindo os escritos pré-carcerários. Para Ives, existem duas razões que o levaram a estudar a linguagem no interior da teoria de Gramsci: o primeiro era o peso teórico da "virada linguística" que teve diversos campos das ciências humanas durante o século XX. A segunda razão: "is based on my own more particular interpretation of Gramsci's writings, which is that his interest in the politics of language was a defining influence on his entire though" (IVES, 2004, p. 1).

\footnotetext{
9 É importante ressaltar que Gramsci diferencia os conceitos de língua e linguagem em sua obra, trabalhando-os de maneira diversa em suas análises. O que buscamos demonstrar é que, a partir da glotologia, das questões a respeito da língua italiana, é que ele chegou numa reflexão mais ampla acerca do funcionamento da linguagem de um modo mais geral.
} 
Quando Ives inicia sua interpretação sobre o conceito de hegemonia, ele ressalta que não se deve abandonar as fontes do conceito de hegemonia como dos marxistas russos Plekhanov ou Lenin, mas que não se pode ficar preso ao estudo dessas fontes. O encontro da reflexão desses conceitos com a reflexão linguística de Gramsci, faz com que Ives afirme que para a compreensão do conceito de hegemonia "without an understanding of the linguistic background of the term, many of the contributions that Gramsci makes to Marxist theory are lost" (ibidem, p. 44).

Um outro autor que realizou um estudo sobre a linguística gramsciana foi Alessandro Carlucci. Para o autor:

Gramsci's writings - certainly the Prison Notebooks, but also many of his Letters from Prison - are contributions to political and ideological debates, and especially his newspaper articles were strongly polemical interventions, part of an ongoing 'fight'. Gramsci's linguistic reflections form an integral part of this political and intellectual work, and they need to be studied as such. (CARLUCCI, 2013, p. 2)

Mas, conforme Carlucci, a "reflexão linguística de Gramsci" não pode ser compreendida isolada das "outras partes" do seu pensamento político, nem da sua prática política, tendo que ser estudada como uma parte, importante, mas não "autônoma" do seu pensamento (ibidem).

Diego Bentivegna também afirma que "o problema da linguagem" atravessa toda a reflexão de Gramsci. Nesse sentido, para este autor, é necessário compreender essa dimensão da linguagem para desenvolver os conceitos gramscianos de intelectual, de hegemonia, de Estado, de partido, entre outros. Dessa forma, a questão da linguagem é transversal às reflexões políticas e filosóficas de Gramsci (BENTIVEGNA, 2013, p. 4647).

Existem certas nuances entre os autores citados. Apesar de todos considerarem a linguística como parte importante, e mesmo fundamental do pensamento de Gramsci, somente Lo Piparo a considera como a "matriz" da sua filosofia. Nesse sentido, Lo Piparo afirma o "não-marxismo" de Gramsci. Já os outros autores procuram situar a reflexão de Gramsci no interior do marxismo e também do pensamento de Lenin - Carlucci dedica, em seu livro, toda uma parte para a discussão da política linguística defendida por Lenin na Rússia pós-revolucionária e para a interpretação de Gramsci desta (ibidem, p. 122129).

Como Bentivegna, Carlucci e Ives, também compreendemos que não existe uma "filosofia da linguagem" ou uma "linguística" em estado teórico em Gramsci. O que há é uma reflexão sobre certas questões da língua e, consequentemente, da linguagem e também sobre a ciência linguística em estado prático, por meio de notas e críticas a determinadas teorias linguísticas. Nos Cadernos do Cárcere, essa linguística em estado prático aparece: i. por meio da análise da formação da língua italiana e sua relação com o latim e os dialetos; ii. na crítica aos neogramáticos e neoidealistas italianos; iii. na crítica à terminologia marxista proposta por Bukharin; iv. na crítica à concepção de gramática de Benedetto Croce; entre outros temas. 
É nesse estado prático que Gramsci compreende a linguagem como concepção de mundo e como processo metafórico.

\section{A linguagem como concepção de mundo para Gramsci}

Na reflexão sobre a filosofia em geral e a filosofia da práxis (nome dado ao marxismo nos Cadernos), em particular, Gramsci afirma que:

É preciso, portanto, demonstrar preliminarmente que todos os homens são 'filósofos', definindo os limites e as características desta 'filosofia espontânea', peculiar a 'todo mundo', isto é, da filosofia que está contida: 1) na própria linguagem, que é um conjunto de noções e de conceitos determinados e não, simplesmente, de palavras gramaticalmente vazias de conteúdo; 2) no senso comum e no bom senso; 3) na religião popular e, consequentemente, em todo o sistema de crenças, superstições, opiniões, modos de ver e de agir que se manifestam naquilo que geralmente se conhece por 'folclore'. ([1932]1999, p. 93)

Neste parágrafo o comunista italiano estabelece uma relação direta entre "filosofia" e "linguagem". A linguagem é compreendida como "um conjunto de noções e de conceitos determinados". Nesse sentido, podemos compreender que a linguagem é posta já nessa relação intrínseca de produção de sentidos e aqui ele fala de "conceitos determinados", de "conjunto de noções", que são justamente os elementos que dão unidade para sua relação com a filosofia.

Com a proposição de que a linguagem é determinada social e historicamente, Gramsci procura se afastar da ideia de que existe uma "língua fixa e universal" (1999, p. 145) expressa, por exemplo, na concepção dos esperantistas ${ }^{10}$. Além disso, afasta-se também da concepção de Pareto e dos pragmatistas que afirmavam a "linguagem como causa do erro" na ciência e na política, isto é, o erro nesses campos tinha como causa uma "incompreensão" ou uma "má interpretação" de determinados termos ou conceitos (ibidem). Contrariamente a essas compreensões da linguagem, Gramsci, ao relacionar linguagem e filosofia, e ao pressupor a existência de diversas filosofias, concebia que as diferentes determinações das "noções e conceitos" presentes na linguagem tinham sua origem nas diferentes filosofias. Nesse sentido, para interpretar o sentido de uma frase formulada por um indivíduo qualquer, camponês ou intelectual acadêmico, é importante realizar a interpretação da "concepção de mundo" ao qual ele, "consciente ou inconscientemente”, faz parte (1999, p. 93-94).

Nessa concepção da linguagem como conjunto determinado de noções e conceitos está inscrita uma compreensão da linguagem como "histórica". Em determinado sentido,

\footnotetext{
${ }^{10} \mathrm{Em} 1918$, Gramsci escreveu um artigo "A língua única e o esperanto" no qual critica a ideia do esperanto como língua internacional e relaciona a mesma com uma concepção positivista do mundo, no qual os esperantistas desejariam "dar forma de manera artificial a una lengua completamente rígida, que no sufra cambios en el espacio y en el tiempo" (2013, p. 54).
} 
está presente a reflexão linguística de Bartoli, seu professor na Universidade de Turim. De acordo com Ives, na formulação de sua ciência linguística, Matteo Bartoli interpretou os aspectos mais culturais e históricos da linguística de Isaia Ascoli (IVES, 2004, p. 46). Nessa interpretação, a língua nacional se desenvolve por meio do conflito com outras línguas e suas mudanças e desenvolvimentos devem ser explicados como "historical result of sociocultural struggle, whether violent or more peaceful" (ibidem).

A essa concepção de linguagem como conjunto de noções e conceitos determinados que é o resultado da luta cultural e filosófica, devemos acrescentar o problema da hegemonia. Como afirma Edmundo Dias, o conceito de hegemonia gramsciano significa "a racionalidade que se faz história" (DIAS, 1996, p. 10). Essa racionalidade é cultural, folclórica, filosófica, econômica, política e também linguística. E essa hegemonia é o fundamento da direção política e ideológica de uma classe (ou um bloco de classes) sobre toda a sociedade.

É, então, partindo dessa compreensão de que a linguagem é histórica e que é um elemento da hegemonia de classe, resultado das relações entre as classes e a institucionalização de determinadas práticas sociais, que podemos compreender a questão da metáfora na obra carcerária de Gramsci.

\section{O processo metafórico da linguagem}

Numa nota intitulada "Linguagem e metáforas", Gramsci critica o Tratado do Materialismo Histórico de Nikholai Bukharin, publicado em 1921. O propósito de Bukharin nesse livro era fornecer um "manual popular" da teoria marxista. Nesse tratado, o comunista russo afirmou o seguinte:

É necessário observar que se encontramos algumas vezes em Marx e Engels definições, que se assemelham exteriormente às condições teleológicas, isto não constitui senão uma metáfora e uma maneira de exprimir um pensamento por imagens: quando Marx diz que o valor é um agregado de músculos, nervos, etc...., somente os adversários mais encarniçados da classe proletária, tais como Pierre Strouve, podem jogar com as palavras e procurar o valor nos próprios músculos. (BUKHARIN, s/d, p. 25-26)

Gramsci considera que essa interpretação de Bukharin, de que os termos "teleológicos" de Marx e Engels constituem uma metáfora no sentido de "exprimir um pensamento por imagens" é uma explicação simplista das formulações dos autores, já que a primeira coisa que Bukharin parece não perceber é que "a linguagem é sempre metafórica":

Talvez não se possa dizer exatamente que todo discurso seja metafórico com relação à coisa ou ao objeto material e sensível referido (ou ao conceito abstrato), a fim de não ampliar demasiadamente o conceito de metáfora; contudo, pode-se dizer que a linguagem atual é metafórica 
com relação aos significados e ao conteúdo ideológico que as palavras tiveram nos períodos anteriores. (GRAMSCI, [1932] 1999, p. 145)

Mas o que significa afirmar que a linguagem é metafórica por excelência? Para Gramsci ela é sempre metafórica, pois os sentidos se transformam historicamente.

Sobre essa questão da metáfora, vale retomar elaborações da análise de discurso, ainda que brevemente. Orlandi, retomando Pêcheux, afirma que "a metáfora está na base da significação. E a metáfora é compreendida, nesse sentido, como efeito de uma relação significante (LACAN, 1966): uma palavra por outra". (ORLANDI, 2007, p. 21). Assim, numa perspectiva discursiva, os sentidos só existem nas relações de metáfora e são produzidos em certa formação discursiva ${ }^{11}$, a qual é o seu lugar mais ou menos provisório. Desse modo, o lugar do sentido, que é lugar da metáfora, é função da interpretação e é espaço da ideologia, conforme Orlandi. Não nos aprofundaremos neste debate no artigo, embora esse seja um dos caminhos de nossa investigação.

Um primeiro elemento tem a ver com a distinção entre "palavra" e "significado". Para Gramsci, não existe um significado rígido dos termos e conceitos. A própria relação entre as diversas filosofias e a linguagem dos sujeitos já aponta para essa distinção. Em cada momento histórico e até no mesmo momento histórico, as palavras podem produzir sentidos ideológicos diferenciados. Dessa forma, Gramsci explica que a utilização da palavra "desastre" não significa que o sujeito-falante seja um adepto da astrologia, campo do qual origina a palavra. Da mesma forma, nenhum ateu pode ser criticado simplesmente pelo uso da palavra "desgraça", de origem religiosa.

Mas não é somente em cada momento histórico. Se a filosofia produz uma linguagem própria, assim como as grandes correntes culturais que disputam a hegemonia política e ideológica, então a relação entre "palavra" e "significado" também tem a ver com essa disputa filosófica. Um analista político marxista e outro liberal não atribuem o mesmo sentido à palavra "Estado" ou "classe" em seus discursos. Aqui reside o centro da crítica gramsciana à interpretação das "metáforas" de Marx e Engels: o sentido de conceitos como "imanente" ou "imanência" não podem ser determinados exclusivamente a partir do estudo da procedência desses termos nas filosofias idealistas. Essa é apenas a procedência desses termos, mas não a determinação de seu sentido. Os sentidos dessas metáforas devem ser compreendidos levando-se em conta a análise da filosofia praticada por esses autores: é relacionando o conceito no interior de uma problemática que poderemos apreender o seu sentido.

Um dos autores que Gramsci estudou para chegar a essa compreensão da "linguagem como metáfora", foi o fundador da semântica histórica Michel Bréal. Para

\footnotetext{
${ }^{11}$ Por "formação discursiva" entendemos, conforme Michel Pêcheux que é: "aquilo que, numa formação ideológica dada, isto é, a partir de uma posição dada, determinada pelo estado da luta de classes, determina o que pode e deve ser dito (articulado sob a forma de uma arenga, de um sermão, de um panfleto, de uma exposição, de um programa, etc.) (PÊCHEUX, [1975] 1995, p.160). O sentido é produzido na formação discursiva, a partir de uma posição-sujeito, sendo os indivíduos interpelados em sujeito pela ideologia. Esta relação se dá pelas formações discursivas que representam, no discurso, as formações ideológicas. Assim podemos dizer que os sentidos das palavras não estão "colados" nelas, mas são derivados das formações discursivas em que se inscrevem.
} 
Gramsci, o tratado de semântica de Bréal era "um catálogo, histórica e criticamente reconstruído, das mutações semânticas de determinados grupos de palavras" (GRAMSCI, 1999, p. 145). Zandwaiss (2013), ao tratar da questão da racionalidade humanista em Michel Bréal, retoma também esta referência de Gramsci a Bréal, sobre o funcionamento metafórico da linguagem e que, como ela afirma, tem efeitos importantes para as concepções de linguagem, consideradas em seu aspecto orgânico no interior de uma teoria marxista. A autora afirma ainda que:

Cabe também observar que, para Bréal, a linguagem ordinária precisa ser analisada não somente como um dado, estático, mas, sobretudo, em termos de seus processos de transformação porque aquilo que a transforma é o que a torna dinâmica, viva. Deste modo, seria tarefa essencial do investigador olhar para os fatos de linguagem e, ao mesmo tempo, para as suas transformações, sem estar simplesmente fundamentado em relações de base dedutiva, calcadas nas observações estritas das mudanças, dos deslocamentos que podem ocorrer em suas estruturas internas, já que, segundo Bréal, “a lógica popular", que pode ser entendida como o motor que move a língua, avança em etapas nem sempre visíveis para o filólogo ou para o linguista. (ZANDWAISS, 2013, p. 50)

Nesse sentido, à influência linguística de Ascoli e Bartoli, acrescenta-se também a de Bréal a fim de se conhecer as bases das reflexões linguísticas de Gramsci.

Continuando a polêmica com Bukharin, numa outra nota Gramsci afirma que:

No Ensaio, observa-se que os termos "imanência" e "imanente" são usados na filosofia da práxis, mas que — "evidentemente" - este uso é apenas "metafórico". Muito bem. Mas, com isso, explicou-se o que significam "metaforicamente" imanência e imanente? Por que estes termos continuam sendo usados e não são substituídos? Tão-só pelo horror de criar novos vocábulos? Com frequência, quando uma nova concepção sucede uma anterior, a linguagem precedente continua a ser usada, mas precisamente de maneira metafórica. Toda a linguagem é um contínuo processo de metáforas, sendo a história da semântica um aspecto da história da cultura: a linguagem é, simultaneamente, uma coisa viva e um museu de fósseis da vida e das civilizações passadas. (GRAMSCI, [1932] 1999, p. 156; grifos nossos)

O fato de a linguagem ser ao mesmo tempo "viva" e um "fóssil" é a contradição do próprio processo linguístico: ela traz a marca do passado, seja pelas palavras, seja pelo sentido produzido; mas ao mesmo tempo, ela é transformada a todo momento, junto e autonomamente da cultura, da história. São os grupos sociais em movimento, as lutas culturais, as lutas políticas, as influências de línguas estrangeiras, etc., que permitem essa "vida" para a linguagem, ao mesmo tempo em que deixa marcas, que volta e meia aparecem no discurso dos sujeitos. 
A essa concepção de linguagem, Gramsci a denomina de "conceito crítico e historicista do fenômeno linguístico". Ele contrapõe esse conceito às três concepções predominantes nas ciências da linguagem da época:

1) Uma compreensão de que as palavras são "belas" ou "feias" em si mesmas, por si mesmas. Nesse sentido, os defensores dessa concepção, como o neoidealista italiano Giullio Bertoni, procuravam "cristalizar metáforas" caindo num erro linguístico com caráter estético;

2) Um segundo erro era daqueles que acreditavam na formulação de uma língua universal e fixa como o esperanto. Esses caíram num erro de caráter poético para Gramsci;

3) Um terceiro estava relacionado aos pragmatistas que acreditavam na possibilidade científica (positivistas) de definir os sentidos de uma palavra de uma vez por todas, evitando o erro na análise científica (política, econômica...) pela linguagem...

De fundo, a "concepção crítica e historicista do fenômeno linguístico" tem como propósito criticar as concepções positivistas sobre a linguagem que buscam definir "leis eternas" para o funcionamento de uma língua, expressando, assim, uma concepção estática do funcionamento da linguagem de modo geral.

\section{As metáforas para Gramsci}

Vejamos, por fim e brevemente, alguns movimentos analíticos de Gramsci a respeito das metáforas. Além da discussão sobre a metáfora "imanente", Gramsci analisa outras palavras e também expressões metafóricas. É importante salientar que a discussão de Gramsci tem como alvo Bukharin e sua concepção de que as expressões de Marx só podem ser entendidas em seu sentido "metafórico". Nesses movimentos analíticos, Gramsci aponta para um método de compreensão da linguagem enquanto vida e fóssil ou enquanto uma "fillologia viva" (ibidem, p. 148).

Numa nota intitulada História da terminologia e das metáforas, Gramsci se propõe a analisar o termo "anatomia" utilizado por Marx na seguinte passagem:
A anatomia do ser humano é uma chave para a anatomia do macaco. Por outro lado, os indícios de formas superiores nas espécies animais inferiores só podem ser compreendidos quando a própria forma superior já é conhecida. Do mesmo modo, a economia burguesa fornece a chave da economia antiga etc. Mas de modo algum à moda dos economistas, que apagam todas as diferenças históricas e veem a sociedade burguesa em todas as formas de sociedade. (MARX, [1857-1858] 2011, p. 58)

No fragmento do texto de Marx é possível fazer a seguinte sinonímia: "a anatomia da economia burguesa é a chave da economia antiga". A primeira questão nessa sinonímia é responder: a anatomia na ciência biológica tem o mesmo sentido na ciência crítica marxista? Na ciência biológica, a utilização do termo "anatomia" significou um avanço 
científico, já que começou a diferenciar as espécies não mais por características secundárias e acidentais, de acordo com Gramsci.

Para ele, a justificativa da utilização da metáfora "anatomia" tem um sentido de "popularização" da ciência marxista por meio da formulação de "um esquema de fácil compreensão" (1999, p. 191). Mas essa popularização fez com que, muitas vezes, se recorresse a metáforas por vezes "grosseiras e violentas". Aqui temos uma possível crítica de Gramsci que não é desenvolvida, mas, sobre a qual é possível realizar uma determinada leitura: a simplificação por metáforas pode ser "útil”, mas também perigosa, pois pode se perder a complexidade dos fenômenos caracterizados, tendo como consequência uma análise mecanicista.

Para Gramsci, a compreensão das metáforas deve ser realizada a partir de um "estudo da origem linguístico-cultural", no próprio sentido dado por Bréal em seu ensaio de semântica. Esse estudo

pode ajudar a compreender melhor o próprio conceito, na medida em que esse é relacionado ao mundo cultural, historicamente determinado, do qual surgiu, bem como é útil para determinar o limite da própria metáfora, isto é, para impedir que ela se materialize e se mecanicize. (ibidem, p. 191)

Para explicar as razões que levaram Marx (e em outras ocasiões Engels) a empregar metáforas das ciências naturais na sua explicação histórica e social, Gramsci afirma que na época, as ciências naturais eram o "modelo" de ciências e as ciências sociais queriam "encontrar um fundamento objetivo e cientificamente capaz de lhes fornecer a mesma segurança e energia das ciências naturais" (ibidem). ${ }^{12}$

Um outro termo estudado por Gramsci para discutir o sentido metafórico foi o termo "materialismo". A nota se intitula Questões de nomenclatura e conteúdo. Nela, Gramsci procura explicitar a relação entre uma nova camada de intelectuais e sua relação com a camada de intelectuais precedentes. Ele afirma que, na esfera ideológica, "uma idêntica nomenclatura de conceitos" (ibidem, p. 125) é justamente a unidade entre a velha e a nova camada de intelectuais de uma sociedade. Mas, com a transformação da sociedade e o desenvolvimento dessa camada de intelectuais, é quase sempre provável a transformação dos conceitos, seja em sua forma, seja em seu significado. Em relação a isso, Gramsci afirmou que:

Todavia, deve-se levar em conta que nenhuma nova situação histórica, mesmo a derivada da mudança mais radical, transforma completamente a linguagem, pelo menos em seu aspecto exterior, formal. Mas o conteúdo da linguagem deveria ter mudado, ainda que seja difícil, de imediato, ter consciência exata desta modificação. Por outro lado, o fenômeno é historicamente complexo e se complica graças à existência

\footnotetext{
12 Se ampliarmos essa afirmação de Gramsci, é possível entender as razões nas quais há uma crescente utilização de termos médicos e psicológicos na explicação da política e das ciências humanas: uma legitimidade maior para a própria explicação e não podemos deixar de considerar que aí trabalha a ideologia.
} 
de diversas culturas típicas nos diversos estratos do novo grupo social, alguns dos quais, no terreno ideológico, ainda estão imersos na cultura de situações históricas que precedem, às vezes, até mesmo aquela que foi superada mais recentemente. (ibidem)

Duas consequências podem ser tiradas dessas afirmações de Gramsci. A primeira é que uma nova situação histórica (pós-revolução francesa ou russa, por exemplo) é atravessada por um processo objetivo de transformação do sentido da linguagem e também da sua forma. Mas, o que é mais interessante, é que justamente a mudança de sentido é mais provável, mesmo que de maneira não planejada, inconsciente, do que a mudança da forma da linguagem: no processo revolucionário, e poderíamos acrescentar no próprio processo histórico, o tempo semântico da linguagem se modifica mais rápido do que o tempo ortográfico.

Esse parece ter sido o exemplo do termo materialismo com relação às transformações operadas no conceito por Marx e Engels. Em seu Tratado, Bukharin aproxima o materialismo histórico dos antigos materialismos grego e francês. Gramsci rejeita essa aproximação. A primeira crítica se relaciona à "redução do materialismo histórico ao materialismo metafísico" (ibidem, p. 128). E nessa crítica, ele acrescenta: "Identidade de termos não significa identidade de conceitos" (ibidem). Ao colocar em relevo a diferença entre "termos" e "conceitos", Gramsci procura afirmar justamente que a utilização do termo "materialismo" por Marx e Engels não tem a mesma definição conceitual que o materialismo nos autores anteriores a ele.

A partir dessa diferenciação, Gramsci recupera a obra de Friederich Lange, Historia do Materialismo. Essa é uma obra curiosa para Gramsci: escrita em 1866, Lange buscou sistematizar os princípios básicos do pensamento materialista ao longo da história e, de acordo com essa classificação, excluiu Ludwig Feuerbach e Karl Marx da tradição materialista. Mas, ao mesmo tempo que excluía Marx da tradição materialista, esta obra inspirou diversos marxistas a interpretar a filosofia materialista de Marx. Nesse sentido, Gramsci acrescenta que para a compreensão de um "conceito", de um significado, de um autor: "é sempre necessário recorrer às fontes culturais para determinar o valor exato dos conceitos, já que, sob um mesmo chapéu, podem estar diferentes cabeças" (IBIDEM, p. 129).

\section{Considerações finais}

Como afirmamos anteriormente, este é um trabalho inicial de pesquisa acerca da questão da língua e da linguagem em Antonio Gramsci. Apesar de inicial, consideramos que a exposição realizada já demonstra que existe um bom caminho para ser explorado e aprofundado em futuras pesquisas, já que alguns temas debatidos por Gramsci em sua obra carcerária não foram abordados aqui, como a questão da gramática e também a relação entre a língua nacional e os dialetos, ou mesmo uma discussão mais detalhada da referência que faz Gramsci a Michel Bréal. Assim, nestas considerações finais buscamos sintetizar alguns dos pontos centrais que foram debatidos sobre a linguagem e a metáfora na obra carcerária do comunista italiano. 
A reflexão de Gramsci sobre a linguagem é crítica e historicista, como ele próprio afirma. É crítica pois parte das teorias da linguagem existentes e realiza sua crítica, das suas análises e teorias. Nesse sentido, Gramsci fez uma crítica às teorias neoidealistas, aos neogramáticos e também aos pragmatistas. Mas, ao mesmo tempo, sua reflexão é historicista, pois compreende o desenvolvimento da linguagem a partir das suas transformações no processo histórico - a retomada de Bréal, nesse ponto é importante, já que a dinâmica da mudança interessa mais a Gramsci (luta cultural, filosófica, de classes) do que a própria mudança em si. A junção de ambas as formas de estudo é que constitui a base da reflexão gramsciana.

É a partir dessa concepção crítico-historicista que Gramsci afirma a relação entre a filosofia e a linguagem. Nessa afirmação há uma distinção entre os "termos" e os "conceitos" e uma compreensão de que, na história, há uma contínua transformação dos significados das palavras por meio de revoluções, lutas políticas, lutas ideológicas, relações culturais e de hegemonia.

Nesse sentido, a mudança na linguagem é compreendida por meio de um contínuo processo de metáforas: uma palavra por outra, um deslizamento de sentido contínuo na história. Nesse deslizamento, a linguagem se apresenta como algo vivo e um museu de fósseis.

$\mathrm{Na}$ interpretação dos conceitos e metáforas utilizados por um autor, de acordo com Gramsci, é importante uma metodologia que leve em conta a procedência cultural da palavra, as relações entre as linguagens predominantes (literárias, científicas, políticas, etc.) e também as referências intelectuais, em sentido amplo, utilizadas pelo autor em questão. Muitas vezes, como no caso de Marx e Engels, a utilização de metáforas por meio de termos das ciências naturais tem a ver com a construção de uma legitimidade do argumento filosófico e/ou científico. Além disso, para Gramsci, uma metáfora deve ser compreendida sempre como parte de uma concepção de mundo, de uma filosofia e seu sentido não é "imanente" à sua forma, mas ao próprio sentido produzido em uma situação historicamente determinada.

Nossa retomada do caminho traçado por Gramsci se inscreve numa tentativa de contribuir para uma análise materialista das questões em torno da linguagem, pensando que a língua é metafórica em seu processo mesmo, conforme o autor.

\section{Referências bibliográficas}

BIANCHI, A. O laboratório de Gramsci: filosofia, história e política. São Paulo: Alameda, 2008.

BENTIVEGNA, D. Un arcángel devastador: Gramsci, las lenguas, la hegemonia. In: GRAMSCI, A. Escritos sobre el lenguaje. Sáenz Peña: Eduntref, 2013.

BUKHÁRIN, N. Tratado de materialismo histórico. Lisboa: CLB, s/d. 
CARLUCCI, A. Gramsci and Languages. Leiden: Brill, 2013.

DIAS, E.F. Hegemonia: racionalidade que se faz história. Em: DIAS, E.F. et al. O outro Gramsci. São Paulo: Xamã, 1996. p. 9-80.

GRAMSCI, A. Escritos sobre el lenguaje. Sáenz Peña: Eduntref, 2013.

O congresso de Livorno. Escritos Políticos (1921-1926). Rio de Janeiro: Civilização Brasileira, vol. 2, 34-37, [1921] 2004.

Cadernos do Cárcere [v. 1]. Rio de Janeiro: Civilização Brasileira, 1999.

IVES, P. Language and Hegemony in Gramsci. London: Pluto, 2004.

LO PIPARO, F. A lingüística e o não-marxismo de Gramsci. 2008. Disponível em http://www.acessa.com/gramsci/?page=visualizar\&id=941. Acesso em $30 \mathrm{de} \mathrm{dez.} 2016$.

MARX, K. Grundrisse. São Paulo: Boitempo, 2011.

ORLANDI, E. Interpretação: autoria, leitura e efeitos do trabalho simbólico. $5^{\mathrm{a}}$. ed. Campinas: Pontes, 2007.

PÊCHEUX, M. [1975] Semântica e Discurso: uma crítica à afirmação do óbvio. $2^{\mathrm{a}}$. ed. Campinas: Editora da Unicamp, 1995.

ZANDWAIS, A. O funcionamento da subjetividade: um contraponto entre estudos comparatistas e a filosofia da linguagem russo-soviética. Conexão Letras, v. 10, 47-59, 2013.

Artigo recebido em: janeiro de 2017.

Aprovado e revisado em: março de 2017.

Publicado em: abril de 2017.

Para citar este texto:

NOGUEIRA, Luciana; FERNANDES, Renato César Ferreira. Linguagem e metáfora nos Cadernos do Cárcere de Antonio Gramsci. Entremeios [Revista de Estudos do Discurso, on-line], Seção Estudos, Programa de Pós-Graduação em Ciências da Linguagem (PPGCL), Universidade do Vale do Sapucaí (UNIVÁS), Pouso Alegre (MG), vol. 14, p. 167-181, jan. - jun. 2017.

DOI: http://dx.doi.org/10.20337/ISSN2179-3514revistaENTREMEIOSvol14pagina167a181 